\title{
Optimalisasi Komposisi Penyusun Briket Berbahan Lokal Sebagai Pakan Sapi
}

\author{
Suwarno, Maridi, Alanindra Saputra, Dewi Puspita Sari \\ Program Studi Pendidikan Biologi FKIP UNS \\ e-mail: suwarnoswami@yahoo.com
}

\begin{abstract}
Abstrak - Penelitian ini bertujuan untuk mengetahui komposisi optimal bahan dalam pembuatan briket pakan sapi. Penelitian ini menggunakan metode eksperimen dengan analisis deskriptif kuantitatif dan kualitatif dengan rancangan penelitian adalah Rancangan acak lengkap ( RAL ). Teknik pengambilan data dilakukan 3x sehari selama 7 hari. Data yang diambil adalah sisa pakan pada setiap pemberian ransum. Teknik analisis data dengan analisis varians ( ANAVA ). Kesimpulan dari penelitian ini adalah komposisi briket paling optimal adalah pada rancangan percobaan RS3 yaitu dengan komposisi hijauan 50, molase 30, dedak 10 dan garam 10.
\end{abstract}

Kata kunci: briket pakan,pakan lokal,pakan sapi, ransum

Abstract - This study aimed to know optimum composition of material to made briquet of cow woof. This study used experimental method with qualitative and quantitative descriptive analisys with design experiment use completely randomized design. Data collection taken 3 times aday for 7 days. Data taken is food residual each feeding. Data Analisys with ANAVA. The conclusion of the study is optimal composition of briquet is RS3 design experiment with composition $50 \%$ forage, $30 \%$ molasses, $10 \%$ rice bran and $10 \%$ salt.

Key word: feed briquette, local feed, cow feed, feed

\section{PENDAHULUAN}

Ketersadiaan pakan merupakan faktor utama keberhasilan dalam usaha peternakan ruminansia, dalam hal ini adalah peternakan sapi. Pakan ternak yang utama bagi ruminansia adalah berupa hijauan yang dikenal dengan hijauan pakan ternak. Hijauan makanan ternak dapat berupa rumput, jerami, batang jagung, maupun kacang-kacangan yang merupakan limbah (sisa) panen yang jumlahnya sangat melimpah pada waktu musim panen tiba. Limbah sisa panen ini belum termanfaatkan secara optimal. Kadang-kadang hanya dibiarkan membusuk atau dibiarkan hingga kering kemudian di bakar. Sedangkan ketersediaan rumput sangat tergantung oleh musim, terutama rumput yang diambil dari alam tanpa budidaya.

Keadaan seperti di atas sangat menyulitkan bagi para peternak ruminansia. Ketersediaan hijauan pakan tidak tersedia secara kontinyu. Dalam kondisi seperti ini, peternak sangat kewalahan untuk memenuhi kebutuhan pakan ternaknya. Oleh sebab itu, peternak seringkali menjual ternaknya dengan harga yang cukup rendah akibat berat badan ternak yang menurun. Peternak pun mengalami kerugian dan mengalami penurunan kesibukan usaha di bidang peternakan. Kondisi ini mengakibatkan penurunan pendapatan 
dan kerugian financial yang cukup berarti bagi para peternak.

Kendala utama dalam memanfaatkan rumput dan jerami padi pada saat jumlahnya melimpah adalah masalah pengawetan dan penyimpanan. Pengawetan sangat berkaitan dengan pengkondisian rumput dan jerami agar awet simpan dengan batas kandungan air tertentu. Sedangkan penyimpanan sangat berkaitan dengan sifat volumetrik rumput dan jerami. Dalam jumlah yang banyak, sangat membutuhkan tempat untuk penyimpanan, sehingga rumput dan jerami perlu diolah agar volumenya dapat diminimalkan sehingga sangat memungkinkan untuk penyimpanan dalam jumlah yang sangat banyak.

Permasalahan diatas dapat dipecahkan dengan pembuatan briket hijauan pakan ternak dengan bahan baku rumput dan jerami padi. Pembriketan rumput dan jerami padi bertujuan untuk memanfaatkan rumput dan jerami padi pada saat musim penghujan dalam jumlah yang melimpah pada musim panen sebagai cadangan kekurangan rumput pada musim kemarau dengan melalui proses pengeringan, perajangan dan pengepresan. Selain itu, briket hijauan makanan ternak memiliki nilai lebih dalam hal peningkatan nilai kecernaan pada ternak, mudah disimpan dalam jumlah besar, mudah dikemas dan diangkut.

Desa Gabus merupakan desa pertanian lahan kering. Lahan pertanian pada musim penghujan ditanami padi dan berbagai macam tanaman sayuran, kacang, jagung dan singkong. Oleh sebab itu, pada saat musim panen tiba, ketersediaan pakan ternak berupa jerami sangat banyak kita jumpai. Para peternak sapi memanfaatkan jerami padi ini sebagai hijauan pakan ternak, dan menyimpannya sebagai cadangan pakan pada saat musim berikutnya. Akan tetapi para peternak merasa kuwalahan ketika harus menyimpan jerami dalam jumlah banyak. Penyimpnan jerami sangat memakan tempat, sehingga kurang praktis dan efisien.

Pada musim kemarau hanya tanaman singkong saja yang tersisa. Lahan terbengkelai di desa ini juga masih cukup luas. Lahan ini pada musim penghujan banyak ditumbuhi rumput liar, sehingga merupakan lokasi penggembalaan vaforit bagi para peternak. Lokasi ini juga merupakan lokasi merumput bagi para peternak. Namun sayang, lokasi favorit ini akan menjadi gersang dan berupa lahan kering pada musim kemarau.

Hijauan Makanan Ternak (HMT) merupakan hijauan yang biasa diberikan pada ternak sebagai pakan setiap harinya. HMT merupakan sumber serat kasar yang utama. Di dalam sistem pemeliharaan ternak di Desa Gabus Hijauan Makanan Ternak merupakan bagian terbesar dari keseluruhan pakan yang diberikan. Pada umumnya hijauan yang diberikan terdiri dari rumput dan leguminosa yang mudah didapat di sekitar desa.

Rumput untuk makanan ternak umumnya berupa rumput lokal atau rumput asli yang banyak tumbuh di alam dan bukan merupakan rumput budidaya. Lokasi pencarian rumput pada umumnya di padang penggembalaan umum, pematang sawah, pinggir jalan, pinggir hutan, saluran irigasi atau perkebunan. Seiring dengan menyempitnya lading rumput liar, maka ketersediaan rumput di alam pun semakin susah untuk memenuhi kebutuhan pakan para peternak. Apalagi saat musim kemarau tiba, hijauan makanan ternak cukup sulit diperoleh. 


\section{METODE}

Metode dalam penelitian ini adalah eksperimen dengan analisis data deskriptif kualitatif dan kuantitatif dengan rancangan acak lengkap ( RAL ). Teknik analisis data yang digunakan adalah dengan analisis varians ( ANAVA ).Teknik pengambilan data dalam penelitian ini dilakukan dengan melakukan penimbangan sisa pakan yang telah diberikan. Prosedur pengambilan data dilakukan 3x sehari selama 7 hari berturutturut. Cara pemberian pakan pada penelitian ini adalah sebanyak $3 x$ sehari yaitu pagi pada pukul 06.00 , siang pada pukul 12.00 dan sore hari pada pukul 18.00. Jumlah pakan yang diberikan adalah berpedoman pada NRC 1985 tentang pemberian pakan pada hewan ternak yaitu $4,3 \%$ berat badan ternak.

Prosedur dalam pembutan briket adalah sebagai berikut ini:

1. Bahan yang dibutuhkan untuk membuat briket pakan ternak adalah hijauan pakan ternak (dapat berupa rumput maupun jerami) sebanyak $70 \%$, bahan tambahan $30 \%$ dan molase 150 gr per blog.

2. Pengawetan hijauan pakan ternak (rumput atau jermi) adalah dengan membuat jerami sebagai komponen/ bahan pakan dalam bentuk briket pakan ternak. Briket pakan ternak ini merupakan campuran dari jerami dan hijauan $(70 \%)$, dedak, urea, garam atau jerami fermentasi dan konsentrat (30\%), dan molase dengan perbandingan tertentu. Pemadatan dilakukan dengan cara mengepres dengan tekanan tertentu sehingga membentuk blok padat dengan ukuran sesuai dengan kebutuhan.

Berikut ini adalah langkah-langkah pembuatan briket:

1. Rumput, leguminocae dan bahan hijauan dicacah, dengan ukuran 3-5 cm. Tujuannya untuk mempercepat proses pengeringan serta memudahkan dalam pencampuran dengan bahan perekat.

2. Rumput dan bahan hijauan yang sudah dicacah dan leguminosa dikeringkan dibawah sinar matahari (+24 jam).

3. Rumput dan bahan hijauan yang sudah kering dicampur dengan bahan bahan lainnya ( dedak, garam, molase ) sampai rata, kemudian ditambahkan leguminosa yang telah digiling dan konsentrat dan diaduk sampai homogen.

4. Campuran yang sudah homogeny kemudian diletakkan dalam cetakan untuk dipress sesuai dengan ukuran.

5. Briket yang sudah selesai dicetak dibiarkan dalam suhu kamar selama $1 \mathrm{x}$ 24 jam sebelum diberikan pada ternak.

\section{HASIL DAN PEMBAHASAN}

Komposisi bahan pakan yang digunakan dalam rancangan penelitian adalah sebagai berikut: 


\begin{tabular}{|c|c|c|c|c|}
\hline \multirow[t]{2}{*}{ Bahan Pakan } & \multicolumn{4}{|c|}{ Ransum Percobaan } \\
\hline & RS1 & RS 2 & RS 3 & RS 4 \\
\hline $\begin{array}{l}\text { Hijauan Makan Ternak } \\
\text { ( HMT ) }\end{array}$ & 30,00 & 40,00 & 50,00 & 60,00 \\
\hline Molase ( konsentrat ) & 50,00 & 40,00 & 30,00 & 20,00 \\
\hline Dedak & 10,00 & 10,00 & 10,00 & 10,00 \\
\hline Garam & 10,00 & 10,00 & 10,00 & 10,00 \\
\hline Jumlah & 100,00 & 100,00 & 100,00 & 100,00 \\
\hline
\end{tabular}

HMT adalah hijauan yang dapat dimanfaatkan untuk pakan ternak. Beberapa jenis HMT antara lain :

\section{Rumput-rumputan}

Rumput-rumputan yang termasuk dalam HMT ada dua jenis yaitu, rumput lokal dan rumput unggul . Rumput local adalah jenis rumput yang sudah lama beradaptasi dengan kondisi tanah dan iklim di Indonesia. Biasanya rumput ini tumbuhnya menjalar atau perdu kecil, mempunyai daya hasil dan kualitas rendah. Rumput ini sering dijumpai di lahan-lahan pertanian, seperti di pinggir jalan, pinggir hutan maupun di pinggir saluran irigasi.

Rumput unggul adalah jenis rumput yang memang sengaja ditanam karena memiliki keunggulan baik dari daya hasil dan mutunya. Umumnya jenis rumput ini secara fisik relatif besar, tumbuhnya tegak, walaupun ada juga yang menjalar sehingga disebut unggul.

2. Leguminosa

Tanaman leguminosa (legum) adalah semua jenis tumbuhan yang termasuk keluarga kacang-kacangan.
Leguminosa ini sangat baik diberikan pada ternak karena kandungan proteinnya sangat tinggi. Tumbuhan ini mampu mengikat unsur nitrogen (N2) dari udara, sehingga tidak perlu dipupuk dengan pupuk $\mathrm{N}$ seperti urea. Beberapa contoh leguminosa antara lain kaliandra, gamal,lamtoro, kalopo, kembang telang dan lain-lain.

3. Daun-daunan

Tidak hanya menggunakan rumput-rumputan dan tanaman leguminocae ada bagian lain dari tumbuh-tumbuhan yang biasa diberikan pada ternak, misalkan daun nangka, daun dan batang pisang, pucuk tebu dan lain-lain.

Briket pakan berbahan local ini memiliki banyak keunggulan, diantaranya adalah:

a. Bentuk briket yang padat dan ringkas yang memudahkan penanganan, penyimpanan, pengangkutan dan pengawetan.

b. Mampu memberikan nilai tambah karena berbahan local dan mampu memanfaatkan hijauan limbah pertanian. 
c. Memiliki kandungan nutrisi yang cukup dan terjamin ketersediaannya

d. Dapat mengurangi biaya produksi.

Cara pemberian pakan pada penelitian ini adalah sebanyak $3 x$ sehari yaitu pagi pada pukul 06.00, siang pada pukul 12.00 dan sore hari pada pukul 18.00. Jumlah pakan yang diberikan adalah berpedoman pada NRC 1985 tentang pemberian pakan pada hewan ternak yaitu $4,3 \%$ berat badan ternak.

HMT yang dipergunakan dapat diberikan sampai batas tertentu, pembatasaniniperludilakukankarena kualitas hijauan pakan tanaman pangan ini pada umumnya rendah karena kandungan lignoselulosa yang tinggi akibat umur tanaman yang sudah tua. Secara keseluruhan kondisi ini akan mengganggu angka kecernaan zat makanan lainnya didalam ransum yang dikonsumsi ternak ruminan, sehingga jumlah zat makanan dapat dicerna menjadi rendah. Menurut Ensminger (1991), pakan yang berkualitas tinggi lebih mudah dicerna dan mudah melewati saluran pencernaan daripada pakan yang berkualitas rendah.

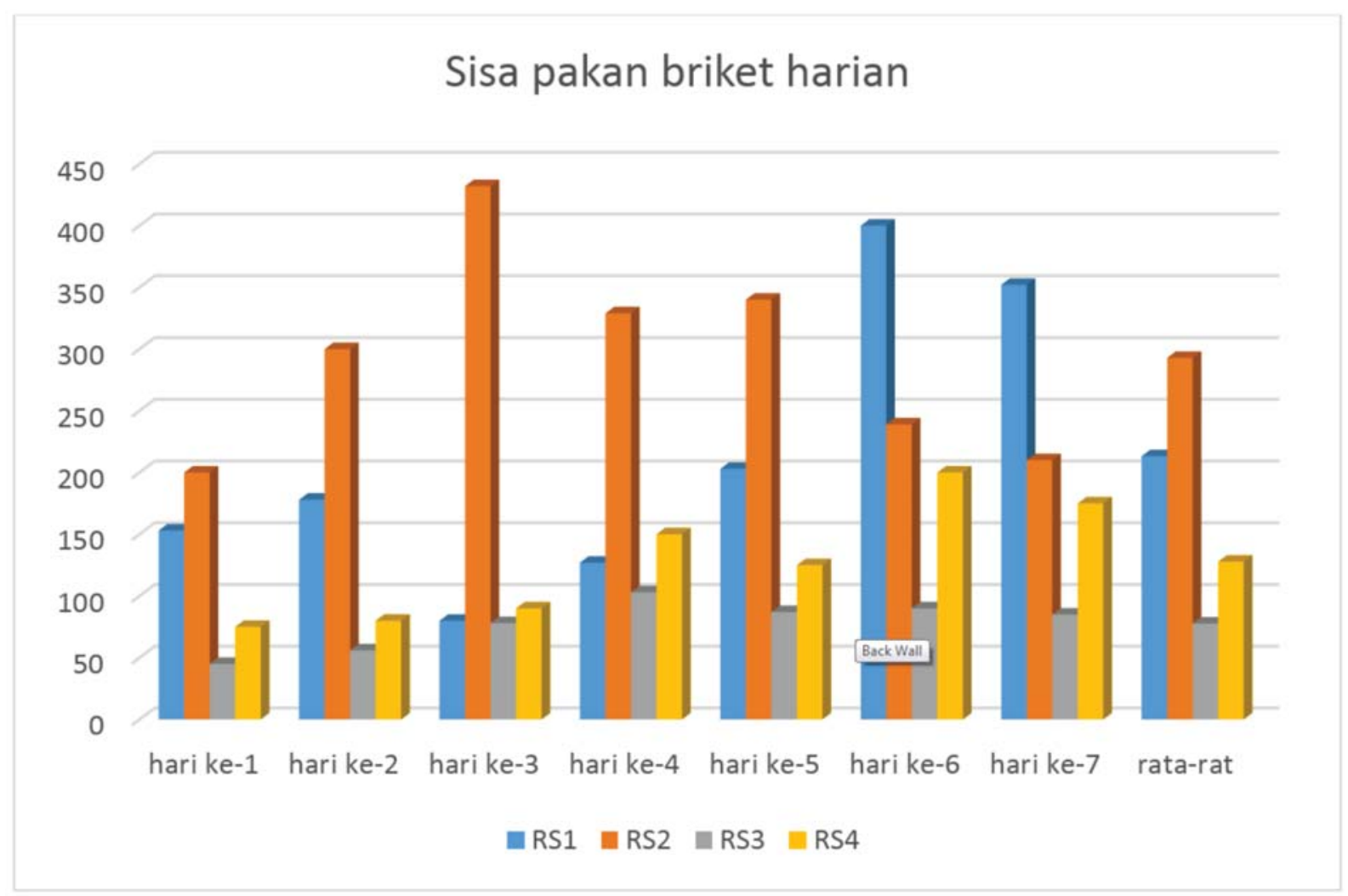

Gambar 1. Tabulasi sisa pakan harian 
Berdasarkan hasil eksperimen ternyata diperoleh bahwa pada perlakuan RS3 dengan perbandingan HMT 50, molase 30, dedak 10 dan garam 10 menunjukkan hasil paling optimal. Hal ini ditunjukkan dengan jumlah sisa pakan harian yang dihasilkan memiliki rata-rata paling kecil. Perlakuan RS3 memiliki sisa pakan paling sedikit, hal ini menunjukkan bahwa pada komposisi itulah yang paling disukai oleh ternak sapi. Sisa pakan yang diperoleh menunjukkan jumlah yang bervariatif, hal ini menandakan bahawa dengan komposisi yang berbeda memberikan tingkat organoleptic yang berbeda pula.

Kekurangan jumlah nutrisi dalam ransum akan memberikan dampak negatif terhadap penampilan produksi ternak, sehingga pola pemanfaatan hijauan pakan ternak harus dilakukan secara strategis dengan melibatkan teknologi pengolahan, penyimpanan, distribusi dan penyusunan ransum yang efisien .

Ransum yang seimbang sesuai dengan tingkat kebutuhan ternak adalah sesuatu hal yang mutlak diberikan jika menginginkan produktifitas ternak yang tinggi. Hal itu harus dipenuhi dalam setiap fase perkembangan ternak ( pertumbuhan, laktasi, penggemukan ). Tentunya hal itu tidak melupakan tentang pertimbangan keekonomisan dari harga pakan tersebut. Penyusunan komposisi ransum sendiri dengan menggunakan bahan lokal yang memiliki kualitas tinggi adalah salah satu cara untuk mengoptimalkan produktifitas usaha ternak.

Mendapatkan komposisi ransum yang seimbang yang memenuhi kebutuhan pokok hidup ternak diperoleh melalui tahapan sebagai berikut ini:

- Menyiapkan tabel kebutuhan zat nutrisi ternak

- Menyiapkan tabel komposisi/ kandungan nutrisi bahan pakan.

- Menyusun formula ransum seimbang

Jenis pakan, konsumsi dan komposisi pakan sangat berpengaruh besar terhadap pertumbuhan ternak. MenurutTimanetal,(1998), pertambahan berat badan akan terjadi apabila pakan yang dikonsumsi telah melampaui kebutuhan untuk hidup pokok, apabila kebutuhan itu sudah terpenuhi, kelebihan nutrisi yang dikonsumsi akan ditimbun sebagai jaringan lemak dan daging ( Cullison, 1979).

Konsumsi pakan ternak ruminansia dibatasi juga oleh jumlah nutrisi yang ada untuk metabolism mereka. Pada tingkat metabolic, konsumsi pakan merupakan bentuk tanggapan terhadap kurangnya jumlah energy dalam tubuh mereka. Sebagai tanggapan dari hal tersebut ternak akan segera mlai makan dan akan berhenti ketika kebutuhan energy yang nereka butuhkan telah tercukupi ( Chuzaemi, 2012 ). Level konsumsi ransum ternak juga dibatasi oleh kebutuhan energy dari hewan ternak, hal ini menunjukkan adanya hubungan serat terhadap tingkat konsumsi, dimana kenaikan tingkat serat akan menurunkan tingkat kecernaan dan ternak akan mengkonsusmsi lebih banayk lagi supaya adapat mencukupi kebutuah energy hidup mereka ( Prakassi, 1999 ).

Sebagian besar pakan ruminansia adalah bahan pakan yang memiliki kadara serat yang tinggi denagn tingkat 
kecernaan yang rendah sehingga harus diupayakan supaya ternak mengkonsumsi pakan dalam jumlah yang besar untuk mencukupi kebutuhan energy hidupnya ( Mc Donald, Edwards dan Greenhalgh, 1973 ). Faktor pakan selain menetukan kecernaan juga sangat menetukan kecepatan aliran pakan meninggalkan rumen. Bahan pakan yang memiliki komposisi serat kasar tinggi akan sangat sulit dicerna sehingga kecepatan alirannya rendah. Adapun factor-faktor yang berpengaruh terhadap kecepatan aliran ransum adalah: factor ternak, komposisi ransum, jumlah ransum, bentuk fisisk ransum dan nilai nutrisi pakan.

Karakteristik pakan seharusnya disesuaikan dengan fungsi rumen sebagai tempat pencernaan bahan pakan berserat tinggi. Pengaturan komposis ransum sangat penting dalam hal ini. Ketika jumlah energi tercukupi maka konsumsi pakan akan berkurang.

\section{KESIMPULAN}

Pemberian ransum pakan briket dengan komposisi HMT 50, Konsentrat (molase )30, dedak 10 dan garam 10 memberikan hasil paling optimal.

\section{DAFTAR PUSTAKA}

Church, D.A. 1984. Livestock Feeds and Feeding. Second Edition. Published and Distributed by O \& B Books Inc. Oregon.

Crampton, E.W., and L.E. Harris. 1969. Applied Animal Nutrition. W.H. Freeman and Company, San Fransisco. p 88.

Cullison, E.A. 1978. Feeds and Feeding Animal Nutrition. Prentice Hall of
India Private Limited. New Delhi. pp. $41-46$

Edey, T.N. 1978. Tropical Sheep and Goat Production. Published by The Australian Universities International Development Program (AUIDP), Canberra. pp. $23-40: 88-104$.

Ensminger, M.E. 1991. Animal Science. Sixth Edition. The Interstate Printers and Publishers. Illinois. p. 714.

Hardianto R, 2003. Pemanfaatan Limbah Pertanian Dan Agroindustri Sebagai Bahan Baku Untuk Pengembangan Industri Pakan Ternak Complete Feed, Materi Program Magang dan Transfer Teknologi Pakan, Balai Pengkajian Teknologi Pertanian, Jawa Timur.

Hartadi, H., R. Reksohadiprodjo., D.A. Tillman, 1990. Komposisi Pakan Untuk Indonesia. Cetakan Kedua. Gadjah Mada University Press. Yogyakarta.

Kearl, L.C. 1982. Nutrient Requirement of Ruminant in Developing Countries. International Feedstuff. Utah Agric Exp Station. Utah State University, Logan. Utah.84332. USA. p. 55.

Musofie, A., N.K. Wardhani., S. Tedjowahjono. 1981. Penggunaan Pucuk Tebu Pada Sapi Bali Jantan Muda. Proseding Seminar Penelitian Peternakan, Bogor.

Muzani A. 2010. Brosur Penggemukan Sapi, Penyediaan Media FEATI, Balai Pengkajian Teknologi Pertanian Nusa Tenggara Barat.

Schneider, B.H. 1975. The Evaluation Of Feed Throught Digestibility 
Experiment. The University of Georgia Press. USA. pp 4, 147, 168169, 252, 261

Steel, R.G.D., and J.H. Torrie, 1980. Prinsip dan Prosedur Analitis Suatu Pendekatan Biometrika. Edisi Kedua. Penerbit PT. Gramedia.

Soebarinoto,S> Chuzaemi dan Mashudi. 1991. Ilmu Gizi Ruminansia. LUW. Animal Husbandry Project. Universitas Brawijaya

Sutardi. T. 1983. Pengelolaan Tatalaksana Makanan dan Kesehatan Sapi Perah. Perhimpunan Dokter Hewan Indonesia Cabang Jawa Barat.

Syahrir.2000.PemanfaatanDaunPucukTebu Ammoniasi Terhadap Kecernaan Zat Makanan Pada Domba Priangan. Thesis. Pascasarjana. Universitas Padjadjaran, Bandung.

Syamsu Jasmal A, 2010. Daya Dukung Limbah Pertanian Sebagai Sumber Pakan Ternak Ruminansia Di Indonesia, Bulletin Peternakan Indonesia, Wartazoa Vol.13 No.1
(2003), Puslitbang Peternakan, Departemen Pertanian.

Usman, Y. 2013. Pemberian pakan serat sisa tanaman pertanian ( jerami kacang tanah, jerami jagung, pucuk tebu ) terhadap evolusi $\mathrm{pH}, \mathrm{N}-\mathrm{NH} 3$ dan VFA di dalam rumen sapi. Jurnal Agripet vol 13 ( 2 ) 53-58

Van Soest, P.J. 1994. Nutrition Ecology of he Ruminant . $2^{\text {nd }}$ Edition. Cornell University Press. New York

Vincent Gasversz. 1991. Analisa Dalam Penelitian Percobaan. Edisi Pertama. Penerbit Tarsito, Bandung.

Wardhani, N.K., S. Tedjowahjono., A. Musofie. 1984. Peranan Pucuk Tebu Sebagai Sumber Pakan Sapi Produksi. Proseding Pertemuan Teknis BP3G. Pasuruan.

Winugroho, M., B. Haryanto., K. Maksum. 1998. Konsep Pelestarian Pasokan Hijauan Pakan Dalam Usaha Optimalisasi Produktifitas Ternak Ruminansia. Seminar Pemanfaatan Pakan Lokal. BPTP Lembang. Bandung. 